\title{
Severity and outcomes of hospitalised community-acquired pneumonia in COPD patients
}

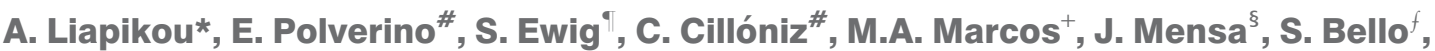 \\ I. Martin-Loeches**, R. Menéndez ${ }^{\# \#}$ and A. Torres ${ }^{\#}$
}

ABSTRACT: Chronic obstructive pulmonary disease (COPD) is a frequent comorbidity in patients with community-acquired pneumonia (CAP). We investigated the impact of COPD on outcomes of CAP patients.

We prospectively studied the clinical presentation of 1,379 patients admitted with CAP during a 4-yr period. A comparative analysis of disease severity and course was performed between 212 patients with COPD, as confirmed by spirometry, and 1,167 non-COPD patients.

COPD patients (mean forced expiratory volume in 1 s $47.7 \pm 16.3 \%$ predicted) were older and more likely to have previously received antibiotics $(37.1 \%$ versus $28.3 \%$; $<0.01)$ than those without COPD. They presented with more severe respiratory failure (arterial oxygen tension/ inspiratory oxygen fraction 270.4 versus 287.8 ; $p<0.01$ ) and more severe pneumonia (pneumonia severity index 118.3 versus $108.5 ; p<0.001$ ) compared with non-COPD patients. However, COPD patients had less multilobar infiltration (44 (21\%) versus $349(30 \%) ; \mathbf{p}<0.01)$ and fewer pulmonary complications (24 (14\%) versus 241 (24\%); p<0.01). A total of 89 (6.5\%) patients died within 30 days. COPD patients had no significant difference in their 30-day mortality rate compared with non-COPD patients (nine $(4.2 \%)$ patients versus $81(7 \%) ; p=0.14)$.

Despite worse clinical presentation, COPD patients had a similar mortality rate compared to non-COPD patients. Previous antibiotic treatment and the decreased incidence of pulmonary complications in COPD may account for these findings.

KEYWORDS: Chronic obstructive pulmonary disease, mortality, pneumonia

hronic obstructive pulmonary disease (COPD) is a frequent comorbidity in patients hospitalised with communityacquired pneumonia (CAP), which may be explained mainly by the altered local and systemic immunity associated with this condition $[1,2]$. Although this respiratory disease is a clear risk factor for $\mathrm{CAP}$, it has not been shown to be a risk factor for mortality [3]. Accordingly, COPD has not been included as one of the five main comorbidities determining the risk of death in the Pneumonia Severity Index (PSI) [4].

A number of clinical and epidemiological studies have been carried out in order to determine the influence of COPD on the mortality of CAP patients, with conflicting results. Whereas two studies do not support COPD as a risk factor for death $[3,5]$, two other studies did show an excess mortality of CAP in patients with COPD $[5,6]$.
Another study in patients with severe CAP treated at an intensive care unit (ICU) also showed an increased risk of mortality [7]. One of the main problems of these studies is the lack of spirometric confirmation of COPD in some patients [4, 7].

Thus, the aim of this prospective study was to determine whether COPD is a risk factor for pulmonary complications and death in patients hospitalised due to CAP. For that purpose, we selected COPD patients with a diagnosis confirmed by spirometry.

\section{METHODS}

\section{Patients}

We prospectively studied 1,379 consecutive adults patients hospitalised with CAP during the period from 2004 to 2008 in the 850-bed tertiary care university hospital (Hospital Clinic,
AFFILIATIONS

*Intensive Care Unit, 'Evaggelismos' Hospital, Athens, Greece. \#Pneumology Dept, Clinic Institute of Thorax (ICT), Hospital Clinic of Barcelona- Insitut d'Investigacions Biomèdiques August Pi i Sunyer (IDIBAPS), University of Barcelona (UB), Ciber de Enfermedades Respiratorias (Ciberes), +Microbiology Laboratory, ${ }^{\S}$ Infectious Diseases, Hospital Clinic, Barcelona

${ }^{f}$ Pneumology Dept, Hospital Miguel Servet, Zaragoza,

${ }^{* *}$ Critical Care Dept, Joan XXIII University Hospital-Ciberes, URV, and IISPV, Mallafre i Guasch, Tarragona, and

\#\#Pneumology Dept, Hospital Universitario La Fe, Valencia, Spain. "Dept of Respiratory Medicine and Infectious Diseases, Thoraxzentrum Ruhrgebiet, Herne and Bochum, Germany.

CORRESPONDENCE

A. Torres

Servei de Pneumologia

Hospital Clinic

Villarroel 186

0806 Barcelona

Spain

E-mail: atorres@ub.edu

Received:

April 192011

Accepted after revision:

Aug 312011

First published online:

Sept 152011 
Barcelona, Spain). Of these, 212 patients with CAP had COPD confirmed by spirometry performed prior to admission. 60 patients were completely excluded from the study since, despite a history of COPD, no previous spirometry had been performed. Absence of COPD was confirmed by previous spirometry and/or clinical history $(n=1,167)$. Moreover, we also excluded those smoking patients on inhaled corticosteroid (ICS) medication, but without asthma, to ensure the exclusion of not clearly diagnosed COPD.

Inclusion criteria were patients with a new radiographic infiltrate and at least two clinical symptoms suggestive of lower respiratory infection. We excluded patients with severe immunosuppression (patients with neutropenia after chemotherapy or bone marrow transplantation, solid-organ transplantation, HIV infection, corticosteroid treatment $>20 \mathrm{mg}$ prednisone equivalent per day for $\geqslant 2$ weeks) and those with nosocomial pneumonia.

The study protocol was approved by the Ethical Committee of the hospital and all patients or their next of kin gave informed consent (registration number 2007/3543).

\section{Definitions}

We defined COPD according to the American Thoracic Society/European Respiratory Society criteria [8].

The classification of COPD severity was based on the Global Initiative for Chronic Obstructive Lung Disease (GOLD) criteria: GOLD stage I was defined as a forced expiratory volume in $1 \mathrm{~s}$ (FEV1) $>80 \%$ predicted, GOLD stage II as FEV1 between 50 and $80 \%$ pred, GOLD stage III as FEV1 between 30 and $50 \%$ pred and GOLD stage IV as FEV1 $<30 \%$ pred [9].

Alcohol abuse was considered in cases with a current intake of $>80 \mathrm{~g} \cdot$ day $^{-1}$ of alcohol in males and $>60 \mathrm{~g} \cdot$ day $^{-1}$ in females [10]. Pulmonary complications were defined as parapneumonic pleural effusion, complicated parapneumonic pleural effusion and empyema requiring chest drainage, lung abscess and acute respiratory distress syndrome at presentation or developed during the first days of hospitalisation. Systemic complications were defined as the presence of renal failure and/or septic shock at presentation or developed during the first days of hospitalisation [11].

Mortality was evaluated 30 days after hospital admission, during follow-up.

\section{Data collection}

Demographic data, coexisting conditions, clinical information and laboratory values were collected at admission. The PSI was used to assess severity of pneumonia on admission [5]. Radiography was used to evaluate the number of lobes involved, the presence of cavitations, atelectasis and pleural effusions.

Follow-up variables were as follows: septic shock; need for invasive mechanical ventilation; pulmonary and systemic complications; systemic steroid treatment; previous antibiotic treatment in the last month; antibiotic treatment as well as duration of treatment; length of hospital stay (LOS) and 30-day mortality.
Samples for microbiological investigation were collected following a standard protocol: 1) blood cultures; 2) urine for Streptococcus pneumoniae and Legionella pneumophila antigen detection; 3) sputum in all patients when possible; 4) tracheobronchial aspirates in all intubated patients; 5) pleural fluid by thoracocentesis; and 6) paired serology when possible to detect seroconversion (i.e. a four-fold increase in immunoglobulin $G$ titres) for Chlamydophyla pneumoniae and $L$. pneumophila $>1: 128$, Coxiella burnetii $>1: 80$ and respiratory viruses (i.e. influenza viruses $A$ and $B$, parainfluenza viruses $1-3$, respiratory syncytial virus and adenovirus).

\section{Statistical analysis}

Categorical variables were described with counts and percentages. For continuous variables, the mean \pm SD was presented. Relationships between categorical variables were studied using the Chi-squared test or Fisher's exact test when necessary. The comparison of continuous variables between two groups was carried out using the t-test for unpaired data once normality was demonstrated (Kolmogorov-Smirnov test); otherwise, the nonparametric test (Mann-Whitney U-test) was used.

The associations of the variables in general characteristics, severity of pneumonia, microbiological diagnosis and evolution of CAP with outcomes were assessed by using the following logistic regression models $[12,13]$.

The first analysis was based on a multivariate logistic regression model with $\mathrm{COPD}$ as the response; $\mathrm{C}$-reactive protein (CRP) and LOS as covariates; and males, ICU admission, diabetes mellitus, pneumonia during previous year, smoking, alcohol, previous antibiotics, ICS use, previous corticoid therapy, PSI classes IV and V, CURB-65 (confusion of new onset, urea $>7 \mathrm{mmol} \cdot \mathrm{L}^{-1}$, respiratory rate of $\geqslant 30$ breaths. $\mathrm{min}^{-1}$, blood pressure $<90 \mathrm{mmHg}$ systolic or diastolic blood pressure $\leqslant 60 \mathrm{mmHg}$, and age $\geqslant 65 \mathrm{yrs}) \geqslant 3$, mechanical ventilation, shock, multilobar involvement, atelectasis, diagnosis, systemic complications, pulmonary complications and corticoid therapy as factors.

The second analysis was based on a multivariate logistic regression model with pulmonary complications as response, CRP as covariate, and males, diabetes mellitus, pneumonia during previous year, COPD severity, smoking, alcohol, previous antibiotics, corticoid inhalers, previous corticoid therapy, PSI classes IV and V, CURB-65 $\geqslant 3$, diagnosis and corticoid therapy as factors.

The third analysis was based on a multivariate logistic regression model with systemic complications as response, CRP as covariate, and males, diabetes mellitus, pneumonia previous year, COPD severity, smoking, alcohol, previous antibiotics, corticoid inhalers, previous corticoids therapy, PSI classes IV and V, CURB-65 $\geqslant 3$, diagnosis and corticoid therapy as factors.

The fourth analysis was based on a multivariate logistic regression model with mortality as response, CRP and LOS as covariates, and males, ICU admission, diabetes mellitus, pneumonia previous year, COPD severity, smoking, alcohol, previous antibiotic, ICS use, previous corticoid therapy, PSI classes IV and V, CURB-65 $\geqslant 3$, mechanical ventilation, shock, 
multilobar involvement, atelectasis, diagnosis and corticoid therapy as factors.

Variables that showed a significant result univariately $(\mathrm{p}<0.1)$ were included in the corresponding multivariate logistic regression backward stepwise model to determine which of them were independently related to prognosis. The HosmerLemeshow goodness-of-fit test was performed to assess the overall fit of the models [12].

All analyses were performed with SPSS 16 for Windows (IBM, Sonek, NY, USA), and a two-sided p-value $<0.05$ was considered to be statistically significant.

\section{RESULTS}

\section{Clinical characteristics}

We identified 1,379 patients hospitalised with CAP with a mean \pm SD age of $70 \pm 17$ yrs. The main characteristics of the patients, comorbidities and disease presentation are shown in online supplementary table 1.

Of the study population, $770(56 \%)$ were smokers (271 exsmokers and 499 current smokers) and $130(9 \%)$ were living in nursing homes. $928(67 \%)$ patients belonged to high-risk classes (PSI classes IV and V). The most frequent comorbidities were lung disease, chronic heart failure and neurological disease (table 1).

COPD was confirmed by spirometry in $212(15 \%)$ patients. The mean \pm SD FEV1 was $48 \pm 16 \%$ pred. The classification of COPD patients into GOLD stages was as follows: stage 1, $\mathrm{n}=13(6 \%)$; stage $2, n=78(37 \%)$; stage $3, n=98(46 \%)$; and stage $4, n=23(11 \%)$.

The differences in baseline characteristics between COPD and non-COPD patients are summarised in table 1. COPD patients with CAP were significantly more likely to be male, were less likely to reside in nursing homes and were more likely to have a history of malignancy and high alcohol consumption. The rate of pneumonia in the previous year was also higher in COPD versus non-COPD patients (71 (34\%) versus 198 (18\%); $\mathrm{p}<0.01)$. COPD patients were more frequently on antibiotics before admission $(76(36 \%)$ versus $322(28 \%)$; $p=0.01)$, ICSs $(137$ $(65 \%)$ versus $148(13 \%) ; \mathrm{p}<0.01)$ and previous oral steroids $(27$ $(13 \%)$ versus $49(4 \%) ; \mathrm{p}<0.01)$.

Non-COPD patients chronically using ICS before admission $(\mathrm{n}=148)$ were mainly affected by asthma $(39 \%)$, bronchiectasis $(15 \%)$, interstitial lung diseases $(12 \%)$ and other chronic respiratory disorders, such as bronchial hyperresponsiveness or tuberculosis sequelae. 12 smoking patients on ICS medication but without asthma were excluded from the study. Similarly, non-COPD patients that had previously been administered oral steroids $(n=49)$ were mostly affected by a chronic non-COPD respiratory disease $(57 \%)$, such as asthma or bronchiectasis, or by other chronic diseases, such as neurological disease (31\%) or a previous neoplastic disease $(18 \%)$.

COPD patients had a higher mean PSI than non-COPD patients (118 versus 109; $\mathrm{p}<0.01$ ), but a similar proportion had a CURB-65 score $\geqslant 3$. They had a worse clinical presentation (respiratory rate and respiratory failure) at admission, but less fever and lower CRP levels (table 2). Likewise, radiographic extension was lower (multilobar infiltrates in $44(21 \%)$ COPD patients versus $349(30 \%)$ non-COPD patients; $\mathrm{p}=0.01)$,

\begin{tabular}{|c|c|c|c|c|}
\hline \multirow{2}{*}{$\begin{array}{l}\text { TABLE } 1 \\
\text { Variable }\end{array}$} & \multicolumn{4}{|c|}{$\begin{array}{l}\text { Clinical characteristics of the study population } \\
\text { stratified according to the presence or absence } \\
\text { of chronic obstructive pulmonary disease } \\
\text { (COPD) }\end{array}$} \\
\hline & & COPD & Non-COPD & p-value \\
\hline \multicolumn{2}{|l|}{ Subjects n } & 212 & 1167 & \\
\hline \multicolumn{2}{|l|}{ Age yrs } & $73.4 \pm 8.8$ & $69.4 \pm 17.9$ & 0.49 \\
\hline \multicolumn{2}{|l|}{ Males } & $191(90.1)$ & $635(54.4)$ & $<0.01$ \\
\hline \multicolumn{2}{|c|}{ Nursing home resident } & $12(5.7)$ & $118(10.2)$ & 0.04 \\
\hline \multicolumn{2}{|c|}{ ICU admission } & $21(9.9)$ & $125(10.7)$ & 0.73 \\
\hline \multicolumn{2}{|c|}{ Mechanical ventilation } & $10(4.7)$ & $61(5.2)$ & 0.76 \\
\hline \multicolumn{2}{|c|}{$\begin{array}{l}\text { Noninvasive mechanical } \\
\text { ventilation }\end{array}$} & $16(7.5)$ & $45(3.9)$ & 0.02 \\
\hline \multicolumn{2}{|c|}{ PSI } & $118.3 \pm 34.1$ & $108.5 \pm 36.9$ & $<0.01$ \\
\hline \multicolumn{2}{|c|}{ PSI classes IV+V } & $159(75.4)$ & $769(65.9)$ & 0.01 \\
\hline \multicolumn{2}{|c|}{ CURB-65 $\geqslant 3$} & $55(27.5)$ & $286(25.7)$ & 0.60 \\
\hline \multicolumn{5}{|c|}{ Comorbid conditions } \\
\hline \multicolumn{2}{|c|}{ Heart failure } & $56(26.4)$ & $267(23.0)$ & 0.28 \\
\hline \multicolumn{2}{|c|}{ Chronic liver disease } & $12(5.7)$ & $48(4.1)$ & 0.32 \\
\hline \multicolumn{2}{|c|}{ Malignancy } & $28(13.2)$ & $66(5.7)$ & $<0.01$ \\
\hline \multicolumn{2}{|c|}{ Renal failure } & $19(9.0)$ & $78(6.7)$ & 0.24 \\
\hline \multicolumn{2}{|c|}{ Neurological disease } & $46(21.7)$ & $318(27.2)$ & 0.09 \\
\hline \multicolumn{2}{|c|}{ Diabetes mellitus } & 55 (25.9) & $234(20.2)$ & 0.06 \\
\hline \multicolumn{2}{|c|}{ Pneumonia during previous year } & $71(33.8)$ & $198(17.5)$ & $<0.01$ \\
\hline \multicolumn{5}{|c|}{ COPD severity } \\
\hline \multicolumn{2}{|c|}{ Mild } & $13(6.1)$ & & \\
\hline \multicolumn{2}{|c|}{ Moderate } & $78(36.8)$ & & \\
\hline \multicolumn{2}{|c|}{ Severe } & $98(46.2)$ & & \\
\hline \multicolumn{2}{|c|}{ Very severe } & $23(10.8)$ & & \\
\hline \multicolumn{2}{|c|}{ History of smoking ${ }^{\#}$} & 202 (95.3) & $568(48.7)$ & $<0.01$ \\
\hline \multicolumn{2}{|c|}{ History of alcohol" } & 63 (34.2) & $197(17.9)$ & $<0.01$ \\
\hline $\begin{array}{l}\text { Previous an } \\
\text { month }\end{array}$ & jiotic in the last & $76(37.1)$ & $322(28.3)$ & 0.01 \\
\hline Previous IC & therapy & $137(64.9)$ & $148(12.9)$ & $<0.01$ \\
\hline Previous or & corticoid therapy & 27 (12.9) & $49(4.2)$ & $<0.01$ \\
\hline Physical an & laboratory data & & & \\
\hline FEV $1 \%$ pr & & $47.7 \pm 16.3$ & & \\
\hline Confusion & & $51(24.2)$ & $326(28.1)$ & 0.24 \\
\hline Respirator & ate $>30$ breaths $\cdot \mathrm{min}^{-1}$ & $89(43.4)$ & $385(34.4)$ & 0.01 \\
\hline $\begin{array}{l}\text { Systolic bl } \\
<90 \mathrm{mn}\end{array}$ & $\begin{array}{l}\text { d pressure } \\
g\end{array}$ & $9(4.3)$ & $61(5.3)$ & 0.56 \\
\hline Heart rate & 120 beats $\cdot \mathrm{min}^{-1}$ & $27(12.8)$ & $161(13.9)$ & 0.67 \\
\hline Fever & & $157(75.1)$ & $960(82.9)$ & 0.01 \\
\hline Temperatu & $>39^{\circ} \mathrm{C}$ & $18(8.5)$ & $148(12.8)$ & 0.08 \\
\hline $\mathrm{Pa}, \mathrm{O}_{2} / \mathrm{Fl}_{1} \mathrm{O}_{2}$ & & $270.4 \pm 67.6$ & $287.8 \pm 72.3$ & $<0.01$ \\
\hline $\mathrm{CRP} \mathrm{mg} \cdot \mathrm{c}$ & & $17.4 \pm 12.3$ & $20.5 \pm 17.6$ & $<0.01$ \\
\hline
\end{tabular}

Data are presented as mean \pm SD or $n(\%)$, unless otherwise stated. $p$-values in bold indicate statistical significance. ICU: intensive care unit; PSI: Pneumonia Severity Index; CURB-65: confusion of new onset, urea $>7 \mathrm{mmol} \cdot \mathrm{L}^{-1}$. respiratory rate of $\geqslant 30$ breaths $\cdot \mathrm{min}^{-1}$, blood pressure $<90 \mathrm{mmHg}$ systolic or diastolic blood pressure $\leqslant 60 \mathrm{mmHg}$, and age $\geqslant 65 \mathrm{yrs}$; ICS: inhaled carticosteroid; FEV1: forced expiratory volume in $1 \mathrm{~s}$; \% pred: \% predicted; $\mathrm{Pa}_{1} \mathrm{O}_{2}$ : arterial oxygen tension; $\mathrm{Fl}, \mathrm{O}_{2}$ : inspiratory oxygen fraction; CRP: C-reactive protein. ${ }^{\#}$ : includes former and current smoking habit; " includes former and current alcohol habit. 
and pleural effusions (19 (11\%) COPD patients versus $168(16 \%)$ non-COPD; $\mathrm{p}=0.07)$ and empyema ( 0 versus $4 \%, \mathrm{p}=0.01$ ) were less frequent in COPD patients.

\section{Aetiological diagnosis}

Microbiological diagnosis was achieved in 537 (46\%) patients. Blood cultures were diagnostic in 153 (16\%) patients, with 19 $(12 \%)$ having COPD. The most frequent microorganism in both groups was S. pneumoniae. Patients with COPD had more infections attributable to Pseudomonas aeruginosa but fewer attributable to L. pneumophila than non-COPD patients $(\mathrm{p}<0.01$ and $\mathrm{p}=0.04$, respectively) (table 2 ).

No specific microorganisms were significantly associated with pulmonary complications in the course of CAP, except for a trend towards a higher frequency of $P$. aeruginosa (five $(3 \%)$ versus seven $(1.5 \%)$ cases).

With regards to the chronic use of ICS, we observed that Legionella spp. were less frequent among patients using ICS (three $(2 \%)$ versus $41(8 \%)$ cases; $\mathrm{p}=0.02)$ while $P$. aeruginosa was more frequent (six $(5 \%)$ versus six $(1 \%)$ cases; $\mathrm{p}=0.01)$.

\section{Disease evolution}

Pulmonary complications

COPD patients developed pulmonary complications less frequently than non-COPD subjects (24 (14\%) versus 241 $(24 \%)$ patients; $\mathrm{p}<0.01)$. They less frequently presented with multilobar involvement (44 (21\%) versus 349 (30\%) patients; $\mathrm{p}=0.01)$, empyema ( 0 versus $41(4 \%) ; \mathrm{p}=0.01)$ and a trend to

\begin{tabular}{lccc}
\hline TABLE 2 & $\begin{array}{l}\text { Microbiological diagnosis according to chronic } \\
\text { obstructive pulmonary disease (COPD) }\end{array}$ \\
\hline Microorganisms & COPD & Non-COPD & p-value \\
\hline Subjects $\mathbf{n}$ & 212 & 1167 & \\
No diagnosis & $117(55.2)$ & $630(54.0)$ & 0.74 \\
Diagnosis & $95(44.8)$ & $537(46.0)$ & \\
Streptococcus pneumoniae & $36(37.9)$ & $230(42.8)$ & 0.37 \\
Virus spp.\# & $13(13.7)$ & $67(12.5)$ & 0.74 \\
Legionella pneumophila & $2(2.1)$ & $42(7.8)$ & $\mathbf{0 . 0 4}$ \\
Staphylococcus aureus & $0(0.0)$ & $17(3.2)$ & 0.08 \\
Chlamydophila pneumoniae & $2(2.1)$ & $22(4.1)$ & 0.35 \\
Mycoplasma pneumoniae & $2(2.1)$ & $18(3.4)$ & 0.52 \\
Haemophilus influenzae & $1(1.1)$ & $12(2.2)$ & 0.45 \\
Pseudomonas aeruginosa & $7(7.4)$ & $5(0.9)$ & $<0.01$ \\
Klebsiella pneumoniae & $0(0.0)$ & $5(0.9)$ & 1.00 \\
Moraxella catarrhalis & $0(0.0)$ & $2(0.4)$ & 1.00 \\
Escherichia coli & $2(2.1)$ & $7(1.3)$ & 0.54 \\
Others & $12(12.6)$ & $42(7.8)$ & 0.12 \\
Polymicrobial pneumonia" & $18(18.9)$ & $68(12.7)$ & 0.10 \\
\hline
\end{tabular}

Data are presented as $n(\%)$, unless otherwise stated. $p$-values in bold indicate statistical significance. ${ }^{*}$ : influenza $A$, influenza $B$, parainfluenza virus, respiratory syncytial virus and adenovirus. ": two microorganisms were found in 16 patients and three microorganisms were found in two patients in the COPD group; two microorganisms were found in 61 patients and three microorganisms were found in seven patients in the non-COPD group. less pleural effusion (19 (11\%) versus $168(16 \%) ; p=0.07)$ (table 3).

Pulmonary complications were more frequent in patients admitted to the ICU (49 (18\%) versus $61(7 \%) ; \mathrm{p}<0.01)$ and in nursing home patients (33 (13\%) versus $76(8 \%) ; \mathrm{p}=0.03)$, and in those with higher CRP levels at admission $(23.9 \pm 29.3$ versus $\left.18.9 \pm 11.8 \mathrm{mg} \cdot \mathrm{dL}^{-1} ; \mathrm{p}<0.01\right)$.

In univariate analysis, diabetes mellitus, mild/moderate COPD, a history of pneumonia in the previous year, previous chronic therapy with ICSs and systemic steroids were associated with fewer pulmonary complications, while an increased CRP at admission and a known microbiological aetiology were associated with more respiratory complications (online supplementary table 2).

Multivariate analysis revealed that increasing CRP values $\left(+1 \mathrm{mg} \cdot \mathrm{dL}^{-1}\right.$; OR 1.02 , 95\% CI 1.00-1.03) and a known microbiological aetiology (OR 1.6, 95\% CI 1.1-2.1) were risk factors for pulmonary complications while diabetes mellitus (OR 0.62, 95\% CI 0.41-0.95) and chronic use of ICSs (OR 0.54, 95\% CI 0.35-0.84) were protective factors (online supplementary table 2).

\section{Systemic complications}

COPD and non-COPD patients developed a similar rate of systemic complications (25 (14\%) versus 190 (19\%) cases; $\mathrm{p}=0.17)$.

Systemic complications were more frequent in patients admitted to the ICU $(27 \%$ versus $6 \%$; $<0.01)$ and in those requiring mechanical ventilation $(15 \%$ versus $2 \% ; \mathrm{p}<0.01)$. They had a higher PSI (IV-V, $87 \%$ versus $62 \%$; $<0.01$ ) and CURB-65 ( $\geqslant 3,51 \%$ versus $21 \%)$ classes, were more frequently males $(66 \%$ versus $58 \% ; \mathrm{p}=0.03)$, were more frequently alcohol abusers $(26 \%$ versus $19 \% ; \mathrm{p}=0.02)$ and suffered more renal failure $(13 \%$ versus $6 \%$; $<<0.01)$.

At univariate analysis, a history of previous pneumonia in the previous year, prior antibiotic use and ICS use were associated with fewer systemic complications. By contrast, males, alcohol abuse, an increased CRP at admission, higher PSI (class IV and

\begin{tabular}{lccc}
\hline TABLE 3 & $\begin{array}{l}\text { Complications and outcomes of community- } \\
\text { acquired pneumonia in patients with and without } \\
\text { chronic obstructive pulmonary disease (COPD) }\end{array}$ \\
Variable & COPD & Non-COPD & p-value \\
\hline Subjects n & 212 & 1167 & \\
Systemic complications & $25(14.3)$ & $190(18.6)$ & 0.17 \\
Pulmonary complications & $24(14.0)$ & $241(23.6)$ & $\mathbf{0 . 0 1}$ \\
$\quad$ Acute respiratory distress & $1(0.6)$ & $23(2.3)$ & 0.15 \\
Empyema & $0(0.0)$ & $41(4.0)$ & $\mathbf{0 . 0 1}$ \\
$\quad$ Pleural effusion & $19(11.0)$ & $168(16.5)$ & 0.07 \\
Septic shock & $4(2.3)$ & $42(4.1)$ & 0.34 \\
LoS days & $10.2 \pm 8.8$ & $10.3 \pm 9.5$ & 0.49 \\
Mortality & $9(4.2)$ & $81(7.0)$ & 0.14 \\
\hline
\end{tabular}

Data are presented as $\mathrm{n}(\%)$ or mean $\pm \mathrm{SD}$, unless otherwise indicated. $\mathrm{p}$-values in bold indicate statistical significance. LOS: length of hospital stay. 
V), higher CURB-65 (class $\geqslant 3$ ), a known microbiological aetiology and previous intake of oral corticoid therapy were associated with increased systemic complications. COPD severity was not associated with the development of systemic complications (online supplementary table 3).

Multivariate analysis showed that classification into PSI class IV or V (OR 2.7, 95\% CI 1.7-4.4), CURB-65 $\geqslant 3$ (OR 2.8, 95\% CI $1.9-4.1)$ and increasing CRP values $\left(+1 \mathrm{mg} \cdot \mathrm{dL}^{-1}\right.$; OR $1.03,95 \%$ CI 1.01-1.04) were predictors of systemic complications (online supplementary table 3 ).

\section{Outcomes}

No differences were observed in ICU admission $(21$ (10\%) versus $125(11 \%) ; p=0.73)$ and in LOS (10.2 \pm 8.8 versus $10.3 \pm 9.5$ days; $\mathrm{p}=0.49)$ between patients with and without COPD.

A total of nine patients with COPD died compared with 81 patients without COPD. The mortality rate of COPD patients was no different compared with the other CAP patients $(4.2 \%$ versus $7 \%$; $=0.14$ ). After exclusion of nursing home patients from groups, the mortality rates were eight $(4 \%)$ and $57(5.4 \%)$, respectively $(p=0.52)$.

In univariate analysis, the variables significantly associated with mortality at 30 days included admission to the ICU, smoking, alcohol, PSI class IV-V, CURB-65 $\geqslant 3$, mechanical ventilation, shock, multilobar infiltrates, corticosteroid systemic therapy during hospitalisation and LOS (table 4).

Multivariate regression analysis revealed mechanical ventilation (OR 4.2, 95\% CI 2.2-8.2), PSI class IV and V (OR 25.4, 95\%

\begin{tabular}{|c|c|c|c|c|}
\hline TABLE 4 & $\begin{array}{l}\text { nificant predic } \\
\text { nmunity-acqui } \\
\text { multivariate }\end{array}$ & $\begin{array}{l}\text { rs of } 30 \\
\text { d pneu } \\
\text { alysis }\end{array}$ & $\begin{array}{l}\text { day mortality } \mathrm{f} \\
\text { onia at univari }\end{array}$ & $\begin{array}{l}\text { rom } \\
\text { iate }\end{array}$ \\
\hline \multirow[t]{2}{*}{ Variable } & \multicolumn{2}{|c|}{ Univariate } & \multicolumn{2}{|c|}{ Multivariate $\#$} \\
\hline & OR (95\% Cl) & $\mathrm{p}$-value & OR $(95 \% \mathrm{Cl})$ & $\mathrm{p}$-value \\
\hline ICU admission & $2.3(1.3-3.9)$ & $<0.01$ & & \\
\hline Smoking & $0.58(0.38-0.89)$ & 0.01 & $0.51(0.32-0.83)$ & 0.01 \\
\hline Alcohol & $0.54(0.27-1.05)$ & 0.07 & & \\
\hline PSI classes IV+V & $23.6(5.8-96.1)$ & $<0.01$ & $25.4(3.5-187.3)$ & $<0.01$ \\
\hline CURB- $65 \geqslant 3$ & $4.7(2.9-7.4)$ & $<0.01$ & $2.5(1.6-4.1)$ & $<0.01$ \\
\hline $\begin{array}{l}\text { Mechanical } \\
\text { ventilation }\end{array}$ & $5.3(2.9-9.6)$ & $<0.01$ & $4.2(2.2-8.2)$ & $<0.01$ \\
\hline Shock & $3.8(2.1-6.8)$ & $<0.01$ & & \\
\hline $\begin{array}{l}\text { Multilobar } \\
\text { involvement }\end{array}$ & $1.7(1.1-2.7)$ & 0.01 & & \\
\hline $\begin{array}{l}\text { Systemic } \\
\text { corticosteroids }\end{array}$ & $2.3(1.4-3.6)$ & $<0.01$ & & \\
\hline LOS days $(+1)$ & $1.02(1.00-1.03)$ & 0.04 & & \\
\hline
\end{tabular}

p-values in bold indicate statistical significantce. ICU: intensive care unit; PSI: Pneumonia Severity Index; CURB-65: confusion of new onset, urea $>7 \mathrm{mmol} \cdot \mathrm{L}^{-1}$, respiratory rate of $\geqslant 30$ breaths $\cdot \mathrm{min}^{-1}$, blood pressure $<90 \mathrm{mmHg}$ systolic or diastolic blood pressure $\leqslant 60 \mathrm{mmHg}$, and aged $\geqslant 65 \mathrm{yrs}$; LOS: length of hospital stay. ${ }^{*}$ : Hosmer-Lemeshow goodness-of-fit test, $\mathrm{p}=0.36$.
CI 3.5-187.3), CURB-65 $\geqslant 3$ (OR 2.5, 95\% CI 1.6-4.1) and smoking to be protective factors $(\mathrm{OR}=0.58)$, so nonsmoking (OR $0.51,95 \%$ CI $0.32-0.83$ ) is independently associated with death (table 4).

Neither COPD nor the severity of COPD as defined using the classification in GOLD stages (I and II versus III and IV) was significantly associated with mortality either in the univariate or multivariate analyses.

\section{DISCUSSION}

In this study, patients with COPD and CAP did not differ in mortality rate from those without COPD. In fact, although COPD patients presented with more severe pneumonia, as reflected by significantly higher PSI scores, a trend towards an even lower mortality in COPD patients was observed.

The impact of COPD in patients hospitalised with CAP is controversial. In one prospective Spanish study, the mortality was $8 \%$, which did not seem to be in excess of the rates reported for the general population [3]. Accordingly, in a subanalysis of a randomised clinical trial, the mortality was $8 \%$ and was not increased in patients with COPD hospitalised with CAP. However, the patient number was limited and the proportion of COPD patients was higher than usual (57\%) [14]. In a large series of nonresponding CAP patients, MENENDEZ et al. [11] found that COPD was a protective factor against failure of treatment with initial antibiotics. Accordingly, it has recently been reported that, in a series including thousands of hospitalised CAP patients, the mortality of COPD was the lowest $(10 \%)$ compared with several other comorbidities with a mortality of up to $25 \%$ [15]. Conversely, in a retrospective observational study from the USA including 744 patients, 215 of whom had COPD, there was a significantly higher $30-$ and 90-day mortality in COPD patients compared with those without COPD (10.6 versus $8.7 \%$ ) [4]. Likewise, in a prospective multicentre study including 710 patients (244 with COPD), COPD was an independent risk factor for mortality in patients with CAP (OR 2.62) [6].

Besides potential biases in study designs, there are at least three important factors that might account for the conflicting results. First, the definition of COPD was not regularly done using spirometric measurements before admission for CAP, thus introducing a significant potential bias. Secondly, without spirometric measurements, no adjustment for COPD severity can be performed. Finally, inhaled and systemic steroids might fundamentally affect outcomes; however, variations in dosages and difficulties in documenting varying dosages over time make it extremely difficult to adequately control for this confounder [16]. An additional limitation of our study is the impossibility to have spirometry in non-COPD patients prospectively admitted for CAP.

In our study, patients were only defined as COPD patients when spirometries were available before admission, and we excluded patients with a clinical history of COPD and without spirometry. This approach substantially increases the validity of the diagnosis. Conversely, the availability of spirometries allowed the adjustment for COPD severity on multivariate analysis of complications and mortality. We made every effort to capture the history of inhaled and systemic steroid medications and also included this confounder in the multivariate 
analysis. However, we could not exclude the hidden effects of dosage variations over time. Overall, we believe that we have taken these potential confounders into account as far as is possible. In the non-COPD group, COPD was discarded either by a previous spirometry result and/or from clinical history.

Patients with COPD had higher mean PSI classes at presentation but a similar CURB-65 score compared with patients without COPD, mainly because of older age and a higher percentage of male sex and number of comorbidities. Despite the higher PSI class, the mortality was lower. The same results were maintained when nursing home patients were excluded from the study. The paradox in COPD patients of more severe pneumonia by PSI score, but with better clinical outcome, could reflect the fact that PSI is possibly not a good marker of severity of CAP in COPD patients. Otherwise, the level of inflammatory response and the consequent lung injury could be better markers of disease severity in COPD patients. Two main reasons may account for this finding. First, it may be related to the fact that COPD patients more frequently received antibiotics before admission, and this has been shown to be protective against severe CAP $[17,18]$. Accordingly, it has also been demonstrated in a large series of 388,406 CAP patients in Germany that death occurs most frequently within the first day after admission [19]. Conversely, the absence of differences in mortality between COPD and non-COPD patients did not change when we stratified COPD patients according GOLD stages. Secondly, despite a higher PSI in COPD patients, the extension of infiltrates and the amount of inflammatory response was lower. Conversely, parameters of acute respiratory failure (respiratory rate and arterial oxygen tension/ inspiratory oxygen fraction ratio) were more severely compromised in COPD patients. This pattern of findings is best explained by the view that COPD patients might already experience acute respiratory failure with less pulmonary extension of pneumonia because of the pre-morbid chronic respiratory compromise. Moreover, this disproportionate effect of mild inflammatory compromise may account for a dilution of COPD as a risk factor of death [20, 21].

In accordance with this interpretation, COPD patients had fewer pulmonary complications at admission. Previous treatment with ICS failed to be an independent protective factor against mortality, but it was a protective factor against the development of respiratory complications at admission and during hospitalisation. Thus, we cannot discard the possibility that previous administration of ICS is not only a "marker of COPD", but that it may reduce lung inflammatory response resulting in fewer pulmonary complications [22]. In concordance with this hypothesis, different authors have clearly suggested that ICS could diminish CAP severity by modulating the local inflammatory response (lung microenvironment and macrophage activation) [23] and subsequent organ dysfunction [24, 25] and, possibly, could even reduce mortality rate $[26,27]$. Our data do not confirm an association of ICS with mortality, but the observed protective effect against pulmonary complications clearly confirms the hypothesis of a positive influence of ICS on CAP severity.

Adjunctive therapy with corticosteroids can cause an attenuation of the inflammation and may improve outcome [28]. Systemic steroids have an inhibitory effect on cytokine production, and have been proposed as a therapeutic option in pulmonary infection and severe sepsis, mainly in patients with adrenocortical insufficiency. In this study, the treatment with systemic steroids did not affect mortality.

In conclusion, this study showed comparable 30-day mortality between patients with spirometrically confirmed COPD and CAP, and patients without COPD, despite more severe pneumonia at admission (according to respiratory rate, respiratory failure and PSI). More frequent previous antibiotic treatment and the disproportion of amount of acute respiratory failure and radiographic extension in COPD patients are possible explanations for this paradox.

\section{SUPPORT STATEMENT}

Supported by grant 2009 SGR 911, Ciber de Enfermedades Respiratorias (Ciberes CB06/06/0028), an initiative of ISCIII, PI08/0472.

\section{STATEMENT OF INTEREST}

None declared.

\section{REFERENCES}

1 Mandell LA, Wunderink RG, Anzueto A, et al. Infectious Diseases Society of America/American Thoracic Society consensus guidelines on the management of community-acquired pneumonia in adults. Clin Infect Dis 2007; 44: Suppl. 2, S27-S72.

2 Farr BM, Bartlett CL, Wadsworth J, et al. Risk factors for community-acquired pneumonia diagnosed upon hospital admission. British Thoracic Society Pneumonia Study Group. Respir Med 2000; 94: 954-963.

3 Snijders D, van der EM, de GC, Boersma W. The influence of COPD on mortality and severity scoring in community-acquired pneumonia. Respiration 2010; 79: 46-53.

4 Fine MJ, Auble TE, Yealy DM, et al. A prediction rule to identify low-risk patients with community-acquired pneumonia. $N$ Engl J Med 1997; 336: 243-250.

5 Torres A, Dorca J, Zalacaín R, et al. Community-acquired pneumonia in chronic obstructive pulmonary disease. Spanish Multicenter Study. Am J Respir Crit Care Med 1996; 154: 1456-1461.

6 Molinos L, Clemente MG, Miranda B, et al. Community-acquired pneumonia in patients with and without chronic obstructive pulmonary disease. J Infect 2009; 58: 417-424.

7 Rello J, Rodriguez A, Torres A, et al. Implications of COPD in patients admitted to the intensive care unit by communityacquired pneumonia. Eur Respir J 2006; 27: 1210-1216.

8 American Thoracic Society. Standards for the diagnosis and care of patients with chronic obstructive pulmonary disease. Am J Respir Crit Care Med 1995; 152: Suppl. 5, S77-S121.

9 Pauwels RA, Buist AS, Calverley PM, et al. Global strategy for the diagnosis, management, and prevention of chronic obstructive pulmonary disease. NHLBI/WHO Global Initiative for Chronic Obstructive Lung Disease (GOLD) Workshop summary. Am J Respir Crit Care Med 2001; 163: 1256-1276.

10 de Roux A, Cavalcanti M, Marcos MA, et al. Impact of alcohol abuse in the etiology and severity of community-acquired pneumonia. Chest 2006; 129: 1219-1225.

11 Menendez R, Torres A, Zalacain R, et al. Risk factors of treatment failure in community acquired pneumonia: implications for disease outcome. Thorax 2004; 59: 960-965.

12 Hosmer D, Lemeshow S. Applied logistic regression. New York, Wiley, 1989.

13 Collett D. Modelling binary data. New York, Chapman \& Hall/ CRC Texts in Statistical Science, 1991. 
14 Restrepo MI, Mortensen EM, Pugh JA, et al. COPD is associated with increased mortality in patients with community-acquired pneumonia. Eur Respir J 2006; 28: 346-351.

15 Ernst P, Gonzalez AV, Brassard P, et al. Inhaled corticosteroid use in chronic obstructive pulmonary disease and the risk of hospitalization for pneumonia. Am J Respir Crit Care Med 2007; 176: 162-166.

16 Crim C, Calverley PM, Anderson JA, et al. Pneumonia risk in COPD patients receiving inhaled corticosteroids alone or in combination: TORCH study results. Eur Respir J 2009; 34: 641-647.

17 Renom F, Yanez A, Garau M, et al. Prognosis of COPD patients requiring frequent hospitalization: role of airway infection. Respir Med 2010; 104: 840-848.

18 Ruiz M, Ewig S, Marcos MA, et al. Etiology of communityacquired pneumonia: impact of age, comorbidity, and severity. Am J Respir Crit Care Med 1999; 160: 397-405.

19 Ewig S, Birkner N, Strauss R, et al. New perspectives on community-acquired pneumonia in 388406 patients. Results from a nationwide mandatory performance measurement programme in healthcare quality. Thorax 2009; 64: 1062-1069.

20 Calbo E, Valdes E, Ochoa de EA, et al. Bacteraemic pneumococcal pneumonia in COPD patients: better outcomes than expected. Eur J Clin Microbiol Infect Dis 2009; 28: 971-976.
21 Garcia-Vidal C, Calbo E, Pascual V, et al. Effects of systemic steroids in patients with severe community-acquired pneumonia. Eur Respir J 2007; 30: 951-956.

22 Martinez R, Menendez R, Reyes S, et al. Factors associated with inflammatory cytokine patterns in community-acquired pneumonia. Eur Respir J 2011; 37: 393-399.

23 Gutierrez P, Closa D, Piner R, et al. Macrophage activation in exacerbated chronic obstructive pulmonary disease with and without community-acquired pneumonia. Eur Respir J 2010; 36: 285-291.

24 Welte $T$. Inhaled corticosteroids in COPD and the risk of pneumonia. Lancet 2009; 374: 668-670.

25 Annane D, Meduri GU. Corticosteroids for community-acquired pneumonia: time to act! Crit Care 2008; 12: 166.

26 Malo de Molina R, Mortensen EM, Restrepo MI, et al. Inhaled corticosteroid use is associated with lower mortality for subjects with COPD and hospitalized with pneumonia. Eur Respir J 2010; 36: 751-757.

27 Chen D, Restrepo MI, Fine MJ, et al. Observational study of inhaled corticosteroids on outcomes for COPD patients with pneumonia. Am J Respir Crit Care Med 2011; 184: 312-316.

28 Keh D, Boehnke T, Weber-Cartens S, et al. Immunologic and hemodynamic effects of "low-dose" hydrocortisone in septic shock: a double-blind, randomized, placebo-controlled, crossover study. Am J Respir Crit Care Med 2003; 167: 512-520. 